This is the author's final, peer-reviewed manuscript as accepted for publication. The publisher-formatted version may be available through the publisher's web site or your institution's library.

\title{
Melanism in a Chinese population of Harmonia axyridis (Coleoptera: Coccinellidae): a criterion for male investment with pleiotropic effects on behavior and fertility
}

Wang Su, J. P. Michaud, Tan Xiaoling, Leigh Murray, Zhang Fan

\section{How to cite this manuscript}

If you make reference to this version of the manuscript, use the following information:

Su, W., Michaud, J. P., Xiaoling, T., Murray, L., \& Fan, Z. (2013). Melanism in a Chinese population of Harmonia axyridis (Coleoptera: Coccinellidae): A criterion for male investment with pleiotropic effects on behavior and fertility. Retrieved from http://krex.ksu.edu

\section{Published Version Information}

Citation: Su, W., Michaud, J. P., Xiaoling, T., Murray, L., \& Fan, Z. (2013). Melanism in a Chinese population of Harmonia axyridis (Coleoptera: Coccinellidae): A criterion for male investment with pleiotropic effects on behavior and fertility. Journal of Insect Behavior, 26(5), 679-689.

Copyright: @ Springer Science+Business Media New York 2013

Digital Object Identifier (DOI): doi:10.1007/s10905-013-9384-6

Publisher's Link: http://link.springer.com/article/10.1007/s10905-013-9384-6

This item was retrieved from the K-State Research Exchange (K-REx), the institutional repository of Kansas State University. K-REx is available at http://krex.ksu.edu 
1 Melanism in a Chinese Population of Harmonia axyridis

2 (Coleoptera: Coccinellidae): A Criterion for Male

3 Investment with Pleiotropic Effects on Behavior and

4 Fertility

5

6 Wang Su ${ }^{1}$, J.P. Michaud ${ }^{2}$, Tan Xiaoling ${ }^{3}$, Leigh Murray ${ }^{4}$, Zhang Fan ${ }^{1}$

$9{ }^{1}$ Institute of Plant and Environment Protection, Beijing Academy of Agriculture 10 and Forestry Sciences, Beijing, China,

11 Kansas State University, Agricultural Research Center - Hays, 1232 240th Ave,

12 Hays, KS, 67601, USA.

$13{ }^{3}$ State Key Laboratory of Crop Stress Biology on the Arid Areas and Key

14 Laboratory of Crop Pest Management on the Losses Plateau of Ministry of

15 Agriculture, Northwest A\&F University, Yangling, Shaanxi, China

$16{ }^{4}$ Kansas State University, Department of Statistics, 101 Dickens Hall, Manhattan,

$17 \mathrm{KS}, 66506$, USA.

18

Tel: 785-625-3425

20 Email: jpmi@ksu.edu

21

22

23

Received:

Accepted:

24 Published:

Running head: Male mating strategies in Harmonia axyridis 
33 Abstract In Beijing, China, females of Harmonia axyridis are promiscuous but

34 prefer typical (succinea form) males to melanic ones in the spring generation,

35 ostensibly due to the thermal disadvantages of melanism during summer. We

36 used laboratory observations to test whether males invested differentially in

37 females according to their elytral color, and whether male behavior was

38 phenotype-dependent. Video-recording was used to monitor no-choice mating

39 tests between virgin adults in all phenotype combinations and females were

40 isolated post-copula to observe their egg retention times and reproduction over

41 five days. Females tended to wait longer before using the sperm of melanic

42 males, and melanic females delayed longer than succinic females. Melanic

43 males spent longer in copula with succinic than melanic females and the latter

44 received fewer bouts of male abdominal shaking that correlate with sperm

45 transfer, regardless of the phenotype of their mate. Although melanic males

46 abandoned melanic females faster than did succinic males, they remained in

47 copula with females of both phenotypes for a longer period after shaking,

48 suggesting a larger investment in mate guarding by the less-preferred male

49 phenotype. Although female fecundity did not vary among phenotype

50 combinations, egg fertility was lower for females mated to melanic males,

51 suggesting a pleiotropic effect of melanism on male fertility in addition to its

52 effects on male mating behavior.

\section{Keywords}

55

56

57

male mate choice, mate guarding, pleiotropy, reproductive investment 


\section{Introduction}

60

61 In promiscuous insect mating systems, females mate repeatedly with different

62 males, setting the stage for sperm competition (Dickinson 1997; Simmons and

63 Siva-Jothy 1998) that can exert strong selection on male mating behavior and

64 lead to an evolutionary escalation of both intra- and intersexual conflict

65 (Alexander et al. 1997). Consequently, males of promiscuous species may

66 resort to various mating strategies aimed at ensuring or improving their paternity,

67 including post-coital mate-guarding, the production of mating plugs to impede

68 female remating (Thornhill and Alcock 1983) and the use of hormones in seminal

69 fluids to manipulate female reproductive physiology (Eberhard 1996). In

70 promiscuous mating systems, the potential arises for the availability of sperm (or

71 associated seminal fluid proteins) to limit male reproductive success more than

72 mere access to females (Avila et al. 2011). When this occurs, selection may

73 favor males that invest differentially in females according to their quality,

74 assuming that males are able to discriminate traits correlated with female fitness

75 (Edward and Chapman 2011).

$76 \quad$ Many species of Coccinellidae exhibit variable elytral color patterns that

77 often include melanic forms (e.g., Benham et al. 1974; reviewed in Majerus 1998

78 and Sloggett and Honek 2012). Melanism influences heat absorption and thus

79 may affect the fitness of insects under different conditions of temperature

80 (Muggleton et al. 1975; Clusella Trullas et al. 2007; Martin-Vega and Arturo

81 2011), hours of sunshine (Brakefield 1984a), and even humidity (Parkash et al.

82 2009). Dark coloration tends to benefit beetles under conditions of low insolation

83 and moderate temperature as absorption of more wavelengths of radiation

84 permits earlier and higher activity levels, thus enhancing foraging activity and

85 reproductive success (Brakefield 1984b). However, melanism is

86 disadvantageous at high temperatures because it impedes an insect's ability to

87 lose excess heat (Stewart and Dixon 1989). Consequently, the frequency of

88 melanic morphs in beetle populations can vary both geographically (Creed 1966; 
89 Davies et al. 2007; Sloggett and Honek 2012) and seasonally (Osawa and

90 Nishida 1992; Nedved and Honek 2012).

91 In many populations of Harmonia axyridis (Pallas) in China and Japan, the

92 frequency of melanic morphs fluctuates seasonally in response to seasonal

93 cycles of female mate preference (e.g., Osawa and Nishida 1992); females of

94 each generation prefer males that possess the background elytral coloration

95 (melanic or succinic) most advantageous for conditions to be faced by progeny in

96 the subsequent generation (Wang et al. 2009). The trait for melanic elytra is

97 controlled by a single dominant gene in $\mathrm{H}$. axyridis (Tan and Li 1934) and

98 evidence exists to suggest that this allele has pleiotropic effects on mating

99 behavior. For example, the strength of a female's preference for the seasonally

100 appropriate male phenotype is influenced by her own elytral color in an adaptive

101 manner (Wang et al. 2009). In the latter study, succinic females breeding in the

102 fall generation showed a stronger non-preference for succinic males than did

103 melanic females because, unlike the latter, the former are unable to produce any

104 melanic offspring unless they mate with a melanic male. The same study

105 revealed that female non-preference can be reflected in longer times to copula,

106 more rejection events, and longer periods of egg retention post-copula when

107 females are presented with less-preferred males. The mechanisms underlying

108 the alternations in mate preference between spring and fall generations are not

109 yet understood, but they appear independent of environmental cues and result in

110 seasonal shifts in the proportion of melanics from $20 \%$ or less in the fall

111 generation to $40-60 \%$ in the spring generation (Wang et al. 2009).

112 It is generally assumed that coccinellid females are largely (but not

113 entirely) in control of the initiation of copula, whereas males control its duration

114 (Wang et al. 2009; Sloggett and Honek 2012). Duration of copula is not a trivial

115 parameter as coccinellids typically spend a very large fraction of their adult lives

116 in mating pairs (Nedved and Honek, 2012). For example, Brakefield (1984a)

117 observed that $23.5-44.0 \%$ of adult Adalia bipunctata L. were in copula at any

118 given time in the field, whereas the observations of Haddrill et al. (2008) yielded

119 an estimate of $20 \%$. Paternity is typically shared by males mating multiply with 
120 the same female, and the duration of copula tends to be correlated with

121 probability of paternity (de Jong et al. 1998; Haddrill et al. 2008).

122 Copulations by pairs of $H$. axyridis typically last two to three hours (Wang

123 et al. 2009; Nedved and Honek 2012). The period of copula can be crudely

124 divided into three sequences of male behavior: (1) the initial latent period (the

125 period from initial genital contact until the first bout of abdominal shaking), (2) a

126 series of stereotyped bouts of abdominal shaking by the male, interspersed with

127 resting intervals, that are assumed to be directly associated with sperm transfer

128 (Obata 1987; Nedved and Honek 2012) and (3) the terminal latent period (the

129 period of sustained genital contact from end of the last shaking bout until the pair

130 separate). In the present experiments, we used continuous video monitoring of

131 individual pairs to measure the frequency and duration of these male behaviors.

132 We used the duration of the terminal latent period as a proxy measurement of

133 male mate-guarding tendency and the duration of copula and number of shaking

134 bouts as estimates of male reproductive investment per female. We

135 hypothesized that spring generation $H$. axyridis males would invest more in

136 succinic females than in melanic and that this preference would be reflected in

137 differences in the duration of copula and in the frequency of male shaking

138 behavior. Secondly, we hypothesized that melanism would have pleiotropic

139 effects on male mating behavior as it does in females, i.e., melanic males reduce

140 their investment in melanic females more than would succinic males. Thirdly, we

141 hypothesized that the less-preferred melanic males would remain longer in

142 copula after sperm transfer was complete, given the risk of their females

143 remating with a male of the preferred phenotype.

144

145 Materials and Methods

147 Insects

149 Adult $H$. axyridis were collected from an apple orchard in rural Beijing, Changping

150 County ( $n=402$ males and 447 females) during April, 2008 and maintained in 
151 the entomology lab of the Institute of Plant and Environment Protection, Beijing

152 Academy of Agriculture and Forestry Sciences. The beetles were held in

153 aluminum frame screen cages $(75.0 \times 45.0 \times 50.0 \mathrm{~cm}), 30$ pairs of adults per

154 cage and reared for a generation prior to production of the experimental insects.

155 The beetles were fed ad libitum on cowpea aphids, Aphis craccivora Koch,

156 reared on Vicia faba L. and refreshed every $48 \mathrm{~h}$. The insects were held under

157 constant environmental conditions of $25 \pm 1 \stackrel{\circ}{\circ} \mathrm{C}, 16: 8 \mathrm{~L}: \mathrm{D}$ daylength, $60-65 \mathrm{RH}$

158 and with light supplied by a 3000 lux LED lamp. The experimental beetles

159 corresponded to a spring generation in which succinic forms are the preferred

160 phenotype (Wang et al. 2009).

161 Over the course of two days, ca. 40 clutches of eggs laid by different

162 females were collected by clipping leaves with egg clusters and transferring them

163 to plastic Petri dishes $(9.0 \mathrm{~cm}$ diameter), one or two clusters per dish. At

164 eclosion, first instar larvae were transferred to a rearing cage (as above), 50

165 larvae per cage. Cowpea aphids were provided as food and once larvae

166 pupated they were isolated in plastic Petri dishes ( $4.5 \mathrm{~cm}$ diameter), one per

167 dish. Newly emerged adults ( $>4 \mathrm{~h}$ post-emergence) were sexed according to

168 the colour of the clypeus, which is pale in males and dark in females (Yu, 2004).

169 The adults for use in experiments were categorized as melanic (elytral

170 background colour black with either two or four large red-orange spots) or

171 succinic (elytra background colour yellow or orange, either immaculate or with

172 variable numbers of small black spots) and maintained as four separate groups

173 in cages (as above): melanic males, melanic females, succinic males, and

174 succinic females. Virgin adults were used in mating experiments when they were

$17515-20$ days old.

176

177 Behavioral Observations

178

179 To examine whether male mating behaviour varied among colour morph

180 combinations, all four phenotype combinations were observed: 1) melanic male +

181 melanic female $\left.\left(\hat{O}_{M}+q_{M}\right), 2\right)$ melanic male + succinic female $\left.\left(\hat{O} \mathrm{M}+q_{\mathrm{S}}\right), 3\right)$ 
182 succinic male + melanic female $\left(\hat{\partial} s+q_{M}\right)$ and 4) succinic male + succinic female

$183(\hat{s} s+q s)$. Environmental conditions were adjusted to mimic natural late spring

184 conditions in Beijing (day $T=16^{\circ} \mathrm{C}$, night $T=11^{\circ} \mathrm{C}, \mathrm{L}: \mathrm{D}=14: 10, \mathrm{RH}=55 \pm$ 185 65\%).

186 For observation, $H$. axyridis adults were paired in plastic Petri dishes (9.0 $187 \mathrm{~cm}$ diameter) with ad libitum food (>0.05 g A. craccivora / dish) and dishes were 188 covered with a layer of perforated parafilm. A HD digital video camera (Sony 189 HDR-FX1E-1080i-Hi vision) fixed on a tripod was then focused on the dish and 190 video was captured on a computer hard drive for subsequent analysis.

191 Video recording was initiated once a male mounted a female and was

192 terminated once the pair separated. We observed 20 mating pairs of each

193 phenotypic combination and tallied data for individual components of male

194 copulation behavior from the video recordings as follows; the initial latent period

195 (the period from genital contact until onset of the first shaking bout), the total

196 duration of copula, and the terminal latent period (the period from the last

197 shaking bout until disengagement of genitalia). A 'shaking bout' was defined as a

198 discrete period of rapid, side-to-side oscillations of the male's abdomen while in

199 copula and the number of shaking bouts was tallied for each mating. Following

200 each observation period, the male was removed, cowpea aphids were

201 provisioned, and all egg clusters laid by the female were collected for five days.

202 Egg clusters were incubated under the same conditions as adults until eclosion 203 and egg fertility was determined.

205 Statistical analysis

207 The seven responses (initial latent period, duration of copula, terminal latent 208 period, number of shaking bouts, egg retention time, fecundity and fertility) were 209 analyzed as a set by 2-way Multivariate Analysis of Variance (MANOVA) with 210 'male' and 'female' phenotypes as fixed factors using the approximate F for Wilks'

211 Lambda. The partial correlation coefficients with t-test statistics were calculated

212 from the MANOVA E-matrix and used to examine correlations between 
213 responses. Responses were then analyzed individually by univariate ANOVA to

214 explain differences seen in the MANOVA. Both MANOVA and ANOVA analyses

215 were conducted using the GLM procedure of SAS (version 9.3). Pairwise mean

216 comparisons of the four different phenotype combinations were done when the

217 overall test of phenotype combinations was significant for the MANOVA and

218 seven ANOVA analyses. To control for Type 1 error for the multivariate and

219 univariate analyses, we used a Bonferroni-adjusted alpha level of $0.05 / 10=$

2200.005 (where 10 is the total number of tests performed).

$221 \quad$ Normality of residuals was also checked for each response using the

222 Univariate procedure of SAS v. 9.3 (SAS Institute 2013) with alpha $=0.01$. Tests

223 of residual normality indicated no problems for all of the response variables

224 except for number of shaking bouts (slight upward skew) and egg retention time

225 (slight downward skew). In addition, the assumption of common variance for the

226 four male ${ }^{\star}$ female combinations was checked using the Brown-Forsythe test in

227 GLM for all response variables, with the result that no response variables

228 displayed nonhomogeneity of variance at an alpha of 0.01 (see Milliken and

229 Johnson, 2009). Given the sample size, the MANOVA and ANOVA results

230 should be robust with respect to slight departures from normality.

\section{Results}

235 The two-way MANOVA analysis (Table 1) showed significant results for the

236 overall model, male and female main effects and the male ${ }^{\star}$ female interaction ( $\alpha$

$237=0.005)$. Pairwise comparisons between the four phenotypes indicated that,

238 based on the set of seven response variables, all phenotypes were highly

239 significantly different from each other except for the $\left(\hat{o} s+q_{s}\right)$ vs $\left(\hat{o} s+q_{M}\right)$

240 comparison $(P=0.0623$; Table 1$)$. Thus, over all responses, melanic males

241 differed in their behavior (and its consequences for female reproduction)

242 according to the phenotype of their mate, whereas succinic males did not. 
244 Table 1. Results of multivariate tests using Wilks' Lambda, Bonferroni correction 245 for multiple pairwise comparisons, $\alpha=0.05 / 6=0.00833$.

246

\begin{tabular}{|c|c|c|c|}
\hline Comparison & $\begin{array}{l}\text { Wilks' Lambda } \\
\text { Approximate } F\end{array}$ & df & $P$ \\
\hline Overall model & 7.23 & $21,86.7$ & $<0.0001$ \\
\hline Male main effect & 16.82 & 7,30 & $<0.0001$ \\
\hline Female main effect & 7.34 & 7,30 & $<0.0001$ \\
\hline Interaction & 3.53 & 7,30 & 0.0070 \\
\hline$\left(\hat{\partial} s+q_{s}\right) v s\left(\hat{s}+q_{M}\right)$ & 2.20 & 7,30 & 0.0623 \\
\hline$\left(\hat{s}+q_{s}\right) v s\left(\hat{M}+\phi_{s}\right)$ & 5.35 & 7,30 & 0.0005 \\
\hline$\left(\hat{s}+q_{s}\right) v s\left(\hat{\partial}_{M}+q_{M}\right)$ & 15.65 & 7,30 & $<0.0001$ \\
\hline$\left(\hat{\partial}_{\mathrm{S}}+\phi_{\mathrm{M}}\right) \mathrm{vs}\left(\hat{\partial}_{\mathrm{M}}+\phi_{\mathrm{S}}\right)$ & 8.51 & 7,30 & $<0.0001$ \\
\hline 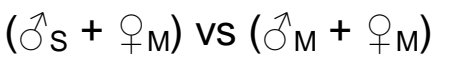 & 14.99 & 7,30 & $<0.0001$ \\
\hline$(\hat{\partial}_{M}+\overbrace{S}) v s(\hat{\partial} M+\overbrace{M})$ & 8.66 & 7,30 & $<0.0001$ \\
\hline
\end{tabular}

The partial correlations obtained in the MANOVA analysis indicated that 249 there were significant correlations for only two pairs of responses. Duration of 250 copula and number of shaking bouts were positively correlated $(R=0.827, P<$ $2510.001)$ as were terminal latent period and fecundity $(R=0.336, P=0.042)$.

252 Clearly, a greater number of shaking bouts cannot occur without a corresponding 253 increase in the duration of copula, but correlation of terminal latent period with 254 fecundity is unclear and may be a chance result without biological significance. 255 The 2-way ANOVA for initial latent period was significant $(F=9.85$; $\mathrm{df}=$ $2563,36 ; P<0.001)$ at alpha $=0.005$, with significant effects of male phenotype $(F=$ 257 28.73; $\mathrm{df}=1,36 ; P<0.001)$ but not female $(F=0.01 ; \mathrm{df}=1,36 ; P=0.945)$, and 258 without a significant interaction $(F=0.82 ; \mathrm{df}=1,36 ; P=0.372)$. Although initial 259 latent periods were relatively short, ranging from 50 -70 seconds, melanic males 260 exhibited significantly longer initial latent periods than succinic males, regardless 261 of female phenotype (Fig. 1A). The overall model was also significant for total 262 duration of copula $(F=20.40 ; \mathrm{df}=3,36 ; P<0.001)$, with significant effects of 263 both male $(F=16.29 ; \mathrm{df}=1,36 ; P<0.001)$ and female $(F=35.89 ; \mathrm{df}=1,36 ; P<$ 
$2640.001)$ phenotype and a significant interaction term $(F=9.01$; $\mathrm{df}=1,36 ; P=$ 265 0.005). Melanic males spent less time in copula with melanic females than did 266 males in other phenotype combinations, with the latter not significantly different 267 from one another (Fig. 1B). The overall model was also significant for the 268 terminal latent period $(F=9.37 ; \mathrm{df}=3,36 ; P<0.001)$ with significant effects of 269 male $(F=26.43 \mathrm{df}=1,36 ; P<0.001)$ but not female $(F=1.65 ; \mathrm{df}=1,36 ; P=$ $2700.207)$ phenotype and a nonsignificant interaction term $(F=0.04 ; \mathrm{df}=1,36 ; P=$ 271 0.842). Melanic males remained coupled with females for longer periods 272 following completion of shaking behavior than did succinic males (Fig. 1C).

273 Two way ANOVA of the total number of shaking bouts yielded a significant 274 overall result $(F=17.12 ; \mathrm{df}=3,36 ; P<0.001)$, with a significant effect of female 275 phenotype $(F=47.19 ; \mathrm{df}=1,36 ; P<0.001)$, but not male $(F=0.22 ; \mathrm{df}=1,36 ; P$ $276=0.643)$, and with an interaction that was close to significance $(F=3.95 ; \mathrm{df}=$ 277 1,36; $P=0.055)$. Succinic females received a larger number of shaking bouts 278 than did melanic females, regardless of the phenotype of the male (Fig. 2A). The 279 overall model was also significant for female egg retention time following pair 280 separation $(F=16.07 ; \mathrm{df}=3,36 ; P<0.001)$, with a significant effect of male 281 phenotype $(F=37.24$; $\mathrm{df}=1,36 ; P<0.001)$, but not female $(F=2.81 ; \mathrm{df}=1,36$;

$282 P=0.103)$, although the interaction term was significant $(F=8.16 ; \mathrm{df}=1,36 ; P=$ 283 0.007). Egg retention times were longest for melanic females that mated with 284 melanic males, followed by succinic females that mated with melanic males (Fig. 285 2B), the latter retaining eggs longer than melanic females mated to succinic 286 males, with $\delta_{s}+q s$ pairs intermediate between these two (Fig. 2B). There was 287 no effect of phenotype combination on female fecundity over the first five days of 288 reproduction (mean $=102 \pm 3.4$ eggs; $F=0.60$; $\mathrm{df}=3,36 ; P=0.622$ ), but there 289 was a significant effect on fertility $(F=8.99$; $\mathrm{df}=3,36 ; P<0.001)$. Male 290 phenotype influenced female fertility $(F=25.80 ; \mathrm{df}=1,36 ; P<0.001)$ but female 291 phenotype did not $(F=0.10 ; \mathrm{df}=1,36 ; P=0.751)$ and the interaction term was 292 nonsignificant $(F=1.07 ; \mathrm{df}=1,36 ; P=0.307)$. Females mating with succinic 293 males hatched a significantly larger proportion of their eggs than did females 294 mating with melanic males (Fig. 2C). 


\section{Discussion}

298 The insects in our experiment corresponded to a spring generation in which

299 succinic males are preferred by females in both choice and no-choice situations

300 (Wang et al. 2009), ostensibly because of the fitness disadvantages incurred by

301 melanic forms under the hot conditions of summer (Brakefield and Wilmer 1987).

302 Female preference for succinic males is reflected in a higher frequency of

303 melanic male rejections and delayed onset of copula, the effect being strongest

304 in melanic females (Wang et al. 2009). In the present study, female preference

305 for succinic males was evident in egg retention times that reflect cryptic female

306 choice (Eberhard 1997); females tended to wait longer to use the sperm of

307 melanic males, and melanic females tended to wait longer than succinic females

308 (Fig. 2B), consistent with previous observations (Wang et al. 2009). Thus

309 melanism is not only a criterion for female mate choice, but also appears to have

310 pleiotropic effects on the strength of the preference in females. An alternative

311 mechanism could be a linkage disequilibrium among loci controlling different

312 traits, which seems less likely when one considers the observed seasonal

313 fluctuations in multiple traits that would require entire gene complexes to flip back

314 and forth in frequency between generations in order to generate the differences

315 observed between spring and fall populations (Wang et al. 2009).

316 Bonduransky (2001) reviewed the evidence for male mate choice in

317 insects and noted that selection for male choosiness should be stronger in

318 systems where female fitness increases with number of copulations, as it does in

319 H. axyridis (e.g., Quinones Pando et al. 2001). Males mating with melanic

320 females spent less time in copula than did their counterparts with succinic

321 females and there was also an effect of male phenotype; melanic males

322 abandoned melanic females sooner than did succinic males (Fig. 1B).

323 Therefore, possession of the melanic allele strengthens mate preference for the

324 succinic phenotype in males much as it does in females, an adaptive pleiotropy

325 given the dominance of the melanic allele (Tan and Li 1934). This finding differs 
326 from previous observations of the same $H$. axyridis population (Wang et al. 2009)

327 in which the duration of copula was relatively invariant among phenotype

328 combinations in no-choice tests, although differences emerged when males were

329 allowed to select females in a choice setting. In the present study, males

330 engaged in fewer shaking bouts with melanic females compared to succinic

331 females regardless of their phenotype (Fig. 1D). Since both duration of copula

332 and bouts of abdominal shaking are correlated with seminal transfer in $\mathrm{H}$.

333 axyridis (Obata 1987), these results supported our hypotheses that males would

334 invest differentially in females based on their elytral coloration, and that melanic

335 males would reduce their investment in melanic females more than succinic

336 males.

$337 \quad$ Even though initial latent periods were likely too short to be of much

338 consequence to male mating strategy, they were significantly longer for melanic

339 males than for succinic males, regardless of female phenotype (Fig. 1A). More

340 significantly, the same pattern was evident for terminal latent periods (Fig. 1C)

341 that were roughly an order of magnitude longer in duration. Thus, melanic males

342 invested more effort in guarding females post-insemination, supporting our third

343 hypothesis. Studies of sperm precedence in Adalia bipunctata suggest that the

344 paternity advantage of the second male can be very high in coccinellids (de Jong

345 et al. 1993). If the probability of female remating is higher following matings with

346 melanic males, as their longer egg retention times would suggest, an increased

347 investment in mate guarding may be an adaptive strategy for melanic males.

$348 \quad$ Interestingly, mating with melanic males reduced female fertility by

349 approximately $25 \%$ relative to matings with succinic males, independent of

350 female phenotype (Fig. 2D), suggesting a negative pleiotropic effect of melanism

351 on male fertility. Rhamhalinghan (1998) reported higher fecundity of melanic

352 females compared to typicals in a polymorphic population of $C$. septempunctata

353 but did not report any differences in fertility. The fitness costs of reduced male

354 fertility, in conjunction with exposure of the melanic allele to selection in

355 heterozygotes, may explain why the equilibrium frequency of the succinic

356 phenotype is approximately 2.5 times that of the melanic in this population of $H$. 
357 axyridis (Wang et al. 2009). Notably, females mated to melanic males did not 358 reduce the number of eggs they laid relative to those mated with succinic males, 359 suggesting that melanism did not influence any putative allohormonal effects of 360 seminal fluids on female fecundity (Eberhard 1997). Aphidophagous coccinellids 361 exhibit a 'front-loaded' distribution of reproductive effort (Dixon and Agarwala

362 2002, Michaud and Qureshi 2006; Vargas et al. 2012), i.e., daily female fecundity

363 is highest early in life and declines thereafter. Thus, it would seem that mated

364 females simply oviposit at a maximal rate once they initiate oviposition,

365 regardless of the relative quality of their most recent mate.

366 To the best of our knowledge, the only previous report of melanism

367 influencing the mating behavior of males was provided by Horth (2003) who

368 observed that melanic male mosquitofish were more sexually aggressive than

369 typical silver males. Although melanism commonly affects activity levels in

370 insects (e.g. Verhoog et al. 1998), it may have no measurable effects on either

371 fitness or mate selection in some species (e.g., Nahrung and Allen 2005). True

372 (2003) reviewed the molecular basis of various melanic pleiotropies in insects

373 and discussed their potential consequences for life history and behavior but

374 found only one reported effect on reproductive success (de Jong et al. 1998:

375 melanic males of $A$. bipunctata require longer copulation times). However, Ma et

376 al. (2008) subsequently examined a spontaneous laboratory example of

377 dominant autosomal melanism in Helicoverpa armigera Hübner and found that

378 melanism was associated with slower development in all juvenile life stages

379 (even though it was only expressed in the pupal and adult stages), lower body

380 weight, lower mating frequency and fecundity, reduced duration of copula, and

381 assortative mating. In contrast, studies of melanism in Mythimna separata

382 (Walker) revealed opposite results; homozygous melanic moths had higher

383 juvenile survival, faster development and greater reproductive success than

384 homozygous typicals (Jiang et al. 2007). Thus, it seems reasonable to expect

385 that other pleiotropic effects of melanism on insect mating behavior remain to be

386 discovered. 
Acknowledgments The authors thank $\mathrm{G}$. Mishra for reviewing the manuscript. This work was funded by the National Basic Research Program of China (2012CB017359) and grant \#31071731 from the National Science Foundation of China.

391

\section{References}

Alexander RD, Marshall DC, Cooley JR (1997) Evolutionary perspectives on insect mating. In: Choe JC, Crespi BJ (eds) The Evolution of Mating Systems in Insects and Arachnids. Cambridge University Press, Cambridge, UK, pp 4-31

Avila FW, Sirot LK, LaFlamme BA, Rubinstein CD, Wolfner MF (2011) Insect seminal fluid proteins: Identification and function. Annu Rev Entomol 56: $21-40$

Benham BR, Lonsdale D, Muggleton J (1974) Is polymorphism in two-spot ladybird an example of non-industrial melanism? Nature 249:179-180

Bonduransky R (2001) The evolution of male mate choice in insects: a synthesis of ideas and evidence. Biol Rev 76:305-339

Brakefield PM (1984a) Ecological studies on the polymorphic ladybird Adalia bipunctata in the Netherlands. I. Population biology and geographical variation of melanism. J Anim Ecol 53:761-774

Brakefield PM (1984b). Ecological studies on the polymorphic ladybird Adalia bipunctata in the Netherlands. II. Population dynamics, differential timing of reproduction and thermal melanism. J Anim Ecol 53:775-790.

Brakefield PM and Wilmer PG (1985) The basis of thermal melanism in the ladybird Adalia bipunctata. Differences in reflectance and thermal properties between morphs. Heredity 54:9-14

Clusella Trullas S, van Wyk JH, Spotila JR (2007) Thermal melanism in ectotherms. J Therm Biol 32:235-245

Creed ER (1966) Geographic variation in the two-spot ladybird in Engalnd and Wales. Heredity 21:57-72. 
418 Davies L, Bouvet S, Vernon P (2007) All-year reproduction and possible thermal melanism in Amblystogenium pacificum (Coleoptera : Carabidae) on the sub-Antarctic Ile de la Possession (lles Crozet). Polar Biol 30:253-260

421 Dickenson JL (1997) Multiple mating, sperm competition, and cryptic female choice in the leaf beetles (Coleoptera: Chrysomelidae). In: Choe JC, Crespi BJ (eds) The Evolution of Mating Systems in Insects and Arachnids. Cambridge University Press, Cambridge, UK, pp 164-183

Dixon AFG, Agarwala BK (2002) Triangular fecundity function and ageing in ladybird beetles. Ecol Entomol 27:433-440

Eberhard WG (1996) Female Control: Sexual Selection by Cryptic Female Choice. Princeton University Press, Princeton, NJ

Eberhard WG (1997) Sexual selection by cryptic female choice in insects and arachnids. In: Choe JC, Crespi BJ (eds) The Evolution of Mating Systems

Edward DA, Chapman T (2011) The evolution and significance of male mate choice. Trends Ecol Evol 26:647-654

435 Jiang XF, Luo LZ, Zhang L (2007) Relative fitness of near isogenic lines for melanic and typical forms of the oriental armyworm, Mythimna separata (Walker). Environ Entomol 36:1296-1301

de Jong PW, Verhoog MD, Brakefield PM (1993) Sperm competition and melanic polymorphism in the 2-spot ladybird, Adalia bipunctata (Coleoptera, Coccinellidae). Heredity 70:172-178 de Jong PW, Brakefield PM, Geerinck BP (1998) The effect of female mating history on sperm precedence in the two-spot ladybird, Adalia bipunctata (Coleoptera: Coccinellidae). Behav Ecol 9:559-565 
447 Horth L (2003) Melanic body colour and aggressive mating behaviour are $448 \quad$ correlated traits in male mosquitofish (Gambusia holbrookı). Proc Roy Soc $449 \quad$ Lond Ser B 270:1033-1040

450 Ma W, Chen L, Wang M, Li X, (2008) Trade-offs between melanisation and lifehistory traits in Helicoverpa armigera. Ecol Entomol 33:37-44 Majerus MEN (1998) Melanism: Evolution in Action. Oxford University Press, $338 \mathrm{pp}$.

Martin-Vega D, Baz A (2011) Variation in the colour of the necrophagous fly, Prochyliza nigrimana (Diptera: Piophilidae): A case of seasonal polymorphism. Eur J Entomol 108:231-234

Michaud JP, Qureshi JA (2006) Reproductive diapause in Hippodamia convergens (Coleoptera: Coccinellidae) and its life history consequences. Biol Control 39:193-200

Milliken GA, Johnson DE (2009) Analysis of Messy Data, Volume 1, Designed Experiments, Second edition. CRC Press, Boca Raton, FL. Muggleton J (1975) Melanism in Adalia bipunctata (Coleoptera: Coccinellidae) and its relationship to atmospheric pollution. J. Appl. Ecology 12:451-464 Nahrung HF, Allen GR (2005) Maintenance of colour polymorphism in the leaf beetle Chrysophtharta agricola (Chapuis) (Coleoptera: Chrysomelidae: Paropsini). J Nat Hist 39:79-90

Nedved O, Honek A (2012) In: Hodek I, van Emden HF, Honek A. (eds) Ecology and Behaviour of the Ladybird Beetles (Coccinellidae). Wiley-Blackwell, Oxford, UK, pp 54-109

Obata S (1987) Mating behaviour and sperm transfer in the ladybird beetle, Harmonia axyridis Pallas (Coleoptera: Coccinellidae). Appl Entomol Zool 22:434-442

476 Parkash S, Singh S. Ramniwas S (2009) Seasonal changes in humidity level in the tropics impact body color polymorphism and desiccation resistance in 
Drosophila jambulina - Evidence for melanism-desiccation hypothesis. J Ins Physiol 55:358-368

480 Quinones Pando FJ, Chavez Sanchez N, Tarango Rivero SH. 2001. Effect of the time of availability of the male in the fecundity of Harmonia axyridis Pallas (Coleoptera: Coccinellidae). Fol. Entomol. Mex. 40: 47-52.

Rhamhalinghan M (1998) The reproductive behaviour of Coccinella septempunctata L. var. Confusa Wiedmann (Coleoptera: Coccinellidae). J Adv Zool 19:17-21

SAS Institute (2013) The SAS System for Windows version 9.3. SAS Institute, Cary, NC

Simmons LW, Siva-Jothy MT (1998) Sperm Compeitition in Insects: Mechanisms and potential for selection. In: Birkhead TR, Moller AP (eds) Sperm Competition and Sexual Selection. Academic Press, San Diego, CA, pp. $341-434$

Sloggett JJ, Honek A (2012) Genetic studies. In: Hodek I, van Emden HF, Honek A. (eds) Ecology and Behaviour of the Ladybird Beetles (Coccinellidae). Wiley-Blackwell, Oxford, UK, pp13-53

Stewart LA, Dixon AFG (1989) Why big species of ladybird beetles are not melanic. Func Ecol 3:165-177

Tan CC, Li JC (1934) Inheritance of the elytral colour patterns in the lady-bird beetle, Harmonia axyridis. Am Nat 68:252-265.

Thornhill R, Alcock J (1983) The Evolution of Insect Mating Systems. iUniverse.com, Lincoln, NE

True JR (2003) Insect melanism: the molecules matter. Trends Ecol Evol 18:640-647

Ueno $H$ (1994) Intraspecific variation of P2 value in a coccinellid beetle, Harmonia axyridis. J Ethol 12:169-174

Vargas G, Michaud JP, Nechols JR (2012) Larval food supply constrains female reproductive schedules in Hippodamia convergens (Coleoptera: Coccinellidae). Ann Entomol Soc Am (accepted) 
508 Wang S, Michaud JP, Zhang RZ, Zhang F, Liu S (2009) Seasonal cycles of 509 assortative mating and reproductive behaviour in polymorphic populations $510 \quad$ of Harmonia axyridis in China. Ecol Entomol 34:483-491.

511

512

513

514 


\section{Figure 1}
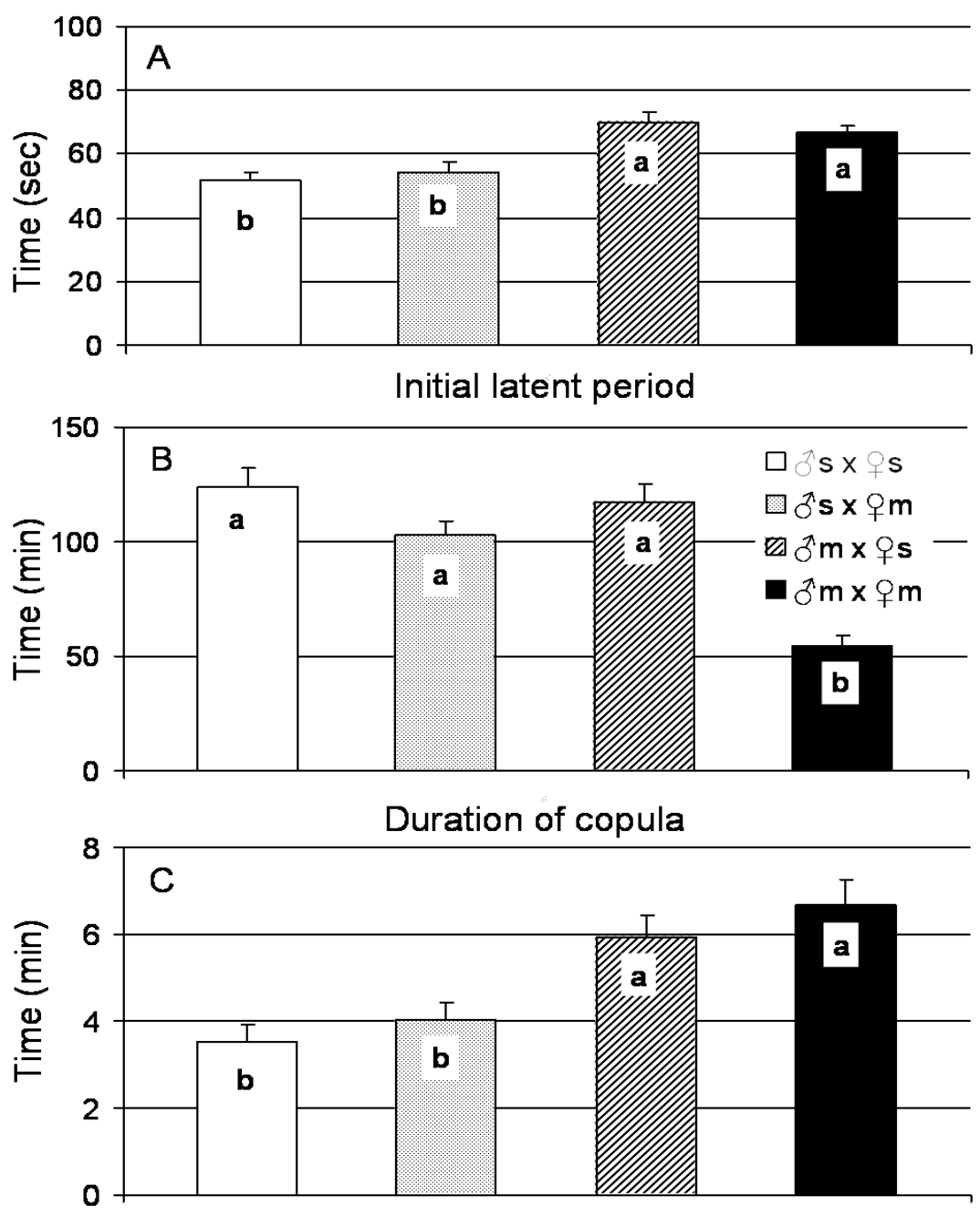

Terminal latent period

517

518 Figure 1. Mean (+SE) initial latent period $(A)$, duration of copula $(B)$, and

519 terminal latent period $(C)$ for matings between various phenotype combinations

520 of $H$. axyridis in no-choice mating tests (succinic $\sigma^{\lambda}+$ succinic + , open columns;

521 succinic $\hat{\sigma}+$ melanic $q$, shaded columns; melanic $\hat{\sigma}+$ succinic $q$, hatched

522 columns; melanic $\hat{\sigma}+$ melanic $q$, solid columns). Columns bearing the same

523 letters were not significantly different (LSD test, $\alpha>0.05$ ). See text for behavior

524 definitions. 


\section{Figure 2}

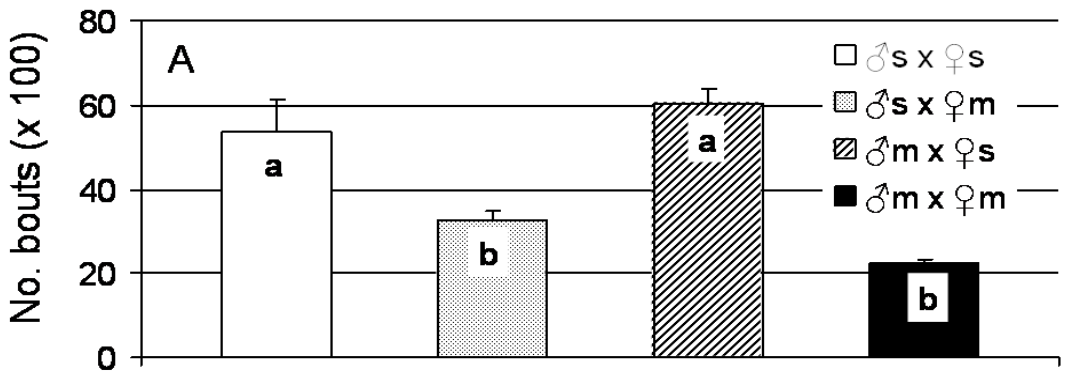

No. shaking bouts

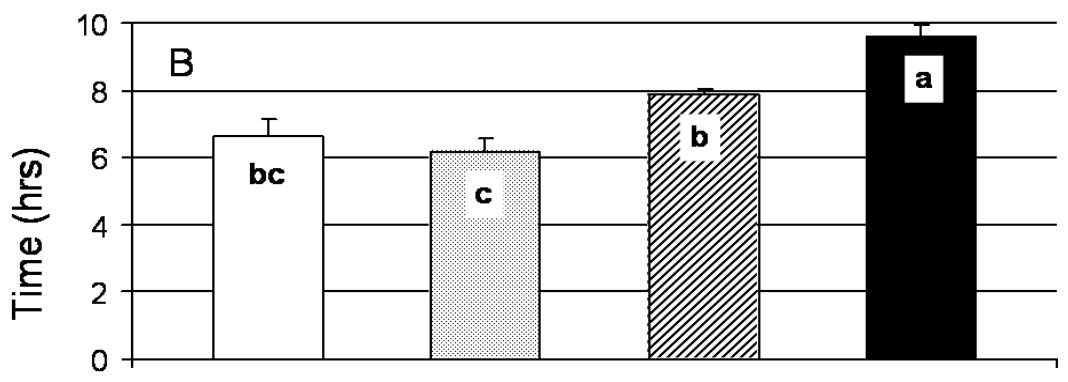

Egg retention time

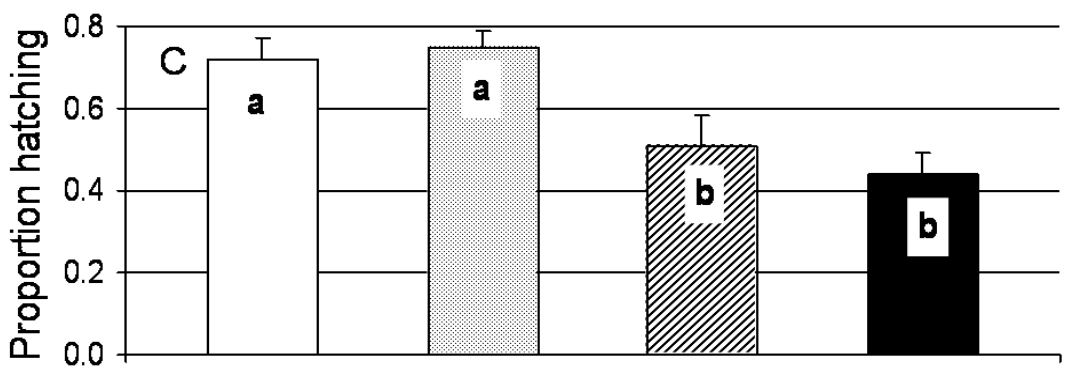

Egg fertility

528 Figure 2. Mean (+ SE) number of male shaking bouts $(A)$, female egg retention

529 time (B) and egg fertility (C) for matings between various phenotype

530 combinations of $H$. axyridis in no-choice mating tests (succinic $\widehat{\sigma}+$ succinic $\bigcirc$,

531 open columns; succinic $\hat{\sigma}+$ melanic $q$, shaded columns; melanic $\hat{\sigma}+$ succinic $q$,

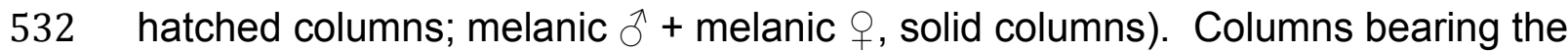

533 same letters were not significantly different (LSD test, $\alpha>0.05$ ). See text for

534 behavior definitions. 